\title{
CONSERVAÇÃO DO LEITE DE CASTANHA-DO-PARÁ ${ }^{1}$
}

\author{
Haíssa Roberta Cardarelli*; Antonio Joaquim de Oliveira ${ }^{3}$ \\ ${ }^{2}$ Pós-Graduanda do Depto. de Ciência e Tecnologia Agroindustrial - USP/ESALQ. \\ ${ }^{3}$ Depto de Ciência e Tecnologia Agroindustrial - USP/ESALQ, C.P. 9 - CEP: 13418-900 - Piracicaba, SP. \\ *Autor correspondente <cardas@uol.com.br>
}

RESUMO: Com o objetivo de avaliar a conservação do extrato fluido da amêndoa de castanha-do-pará (conhecido como leite de castanha), executou-se a pasteurização com e sem adição de conservantes químicos e armazenou-se o produto sob refrigeração. Monitorou-se o produto, ao longo de um período de 180 dias de armazenamento, através de análises microbiológicas e das análises físico-químicas de acidez titulável e de $\mathrm{pH}$. Os tratamentos que receberam conservantes químicos foram os mais estáveis microbiologicamente e obtiveram $\mathrm{pH}$ e acidez titulável mais equilibrados. A ausência de coliformes totais e fecais demonstrou a eficiência da pasteurização. Concluiu-se que a pasteurização só é um método viável de conservação do leite de castanha se associada à adição de conservantes e à refrigeração.

Palavras-chave: Bertholletia excelsa, conservação, castanha-do-pará, leite de castanha

\section{CONSERVATION OF BRAZIL NUT EXTRACT}

\begin{abstract}
Pasteurization of a Brazil nut extract with and without addition of chemical preservatives and the storage of this product under refrigeration was performed to evaluate the conservation of this extract. The product was monitored during 180 days by microbiological, physical and chemical analysis including titratable acidity and $\mathrm{pH}$. Treatments with chemical preservatives were microbiologically stable and titratable acidity and $\mathrm{pH}$ were equilibrated. Absence of total and fecal coliforms demonstrated the pasteurization efficiency. It is concluded that the pasteurization is only a viable method for preservation of the Brazil nut extract when associated with chemical preservatives and refrigeration.

Key words: Bertholletia excelsa, conservation, Brasil nut, Brasil nut milk
\end{abstract}

\section{INTRODUÇÃO}

A castanha-do-pará, ou castanha-do-brasil, semente da castanheira-do-pará, Bertholletia excelsa, H.B. e K., da família das Lecitidáceas, é cultivada em toda a Amazônia e considerada uma das maiores riquezas nas regiões dos castanhais (Vianna, 1972).

Para Locatelli \& Souza (1990), a castanha-do-pará tem alto valor econômico devido ao aproveitamento de suas amêndoas (que contêm cerca de 60 a $70 \%$ de lipídios e 15 a $20 \%$ de proteínas, segundo Ribeiro (1992)) na alimentação humana e animal, "in natura", ou transformadas em vários subprodutos.

O beneficiamento pode ou não ser feito. As castanhas com casca podem ser vendidas desidratadas ou semidesidratadas ou ainda a granel (sem beneficiamento). As castanhas sem casca (amêndoas) são obtidas quebrando-se manualmente e podem ser vendidas com ou sem película. Devido ao formato irregular, há uma grande porcentagem que se quebra (Vianna, 1972). Segundo Sant'anna (1985), aproximadamente 10\% delas se quebram, reduzindo seu valor comercial a apenas $60 \%$ do das castanhas perfeitas e a utilização dessa quantidade, bem como parte da produção na forma de subprodutos, é alternativa para o aproveitamento dessa matéria-prima de alto valor agroindustrial.
Yokoya et al. (1971) consideram que o armazenamento e a conservação da castanha-do-pará constituem os problemas mais importantes para sua comercialização.

Aires et al. (1986) colocam que a castanha representa entre 25 a 30 milhões de dólares anuais de exportação. Sabe-se que quase a totalidade da produção é exportada, principalmente para os Estados Unidos e para o Reino Unido (Ribeiro, 1992).

Dados da Cacex (1984) revelam que a produção nacional de castanha-do-pará representa de 80 a $90 \%$ da produção mundial.

Conforme Ribeiro (1992), a industrialização é incipiente, restrita às áreas de produção entre os castanheiros. Não há fabricação industrial de óleo e aproveitamento de subprodutos. Duas razões para esse reduzido consumo são a baixa qualidade de conservação das sementes (principalmente o ranço) e a dificuldade em se quebrar a casca.

A maior parte da produção de castanha do Pará é extrativa, embora haja plantio racional (Ribeiro, 1992).

Dado o agradável sabor e reconhecido valor nutricional, a castanha-do-pará pode alcançar consumo considerável e mesmo se incorporar ao cotidiano alimentar da população brasileira, sendo para isso necessário seu aproveitamento industrial, obtendo-se um grupo de

${ }^{1}$ Parte da Dissertação de Mestrado da primeira Autora apresentada à USP/ESALQ - Piracicaba, SP. 
produtos novos que preservem as qualidades naturais da castanha e que sejam passíveis de armazenamento por períodos determinados.

Esta pesquisa visa avaliar a conservação do extrato fluido da amêndoa de castanha-do-pará, por pasteurização, adicionado ou não de conservantes químicos e armazenado sob refrigeração, com ênfase no desenvolvimento microbiano e nas características físico-químicas de acidez titulável e $\mathrm{pH}$. Acredita-se poder, assim, contribuir para a utilização de novos produtos, obtidos a partir de subprodutos do processamento da amêndoa para a extração de óleo, na alimentação humana, evitando o desperdício de alimentos e podendo complementar a dieta da população brasileira com uma boa fonte nutricional, inclusive em programas de merenda escolar.

\section{MATERIAL E MÉTODOS}

\section{Delineamento experimental}

A pesquisa consistiu de um experimento que envolveu os seguintes tratamentos:

\section{Tratamentos:}

T1 - ácido cítrico (HII) na proporção de 500 ppm ésteres metil-propil do ácido parahidroxibenzóico (3:1) na proporção de $0,1 \% \mathrm{p} / \mathrm{v}$ sorbato de potássio na proporção de $0,2 \% \mathrm{p} / \mathrm{v}$ pasteurização a $72 \pm 2^{\circ} \mathrm{C}$ por 20 minutos T2 - ácido cítrico na proporção de 500 ppm ácido benzóico na proporção de $0,2 \%$ p/v sorbato de potássio na proporção de $0,2 \%$ p/v pasteurização a $72 \pm 2^{\circ} \mathrm{C}$ por 20 minutos T3 - sem conservantes pasteurização a $72 \pm 2^{\circ} \mathrm{C}$ por 20 minutos

Duas amostras foram retiradas de cada tratamento, ou seja, duas embalagens com $100 \mathrm{ml}$ de leite, para serem analisados em cada período.

Períodos de análise (em dias): 0, 15, 30, 45, 60, 75, 90, 120, 150 e 180.

A combinação de conservantes utilizada baseouse, inicialmente, nos conservantes utilizados no leite de coco pasteurizado, conforme cita Teixeira et al. (1989), que são: ácido cítrico, ácido benzóico, ácido sórbico e metabissulfitos.

\section{METODOLOGIA}

\section{Obtenção do leite}

A obtenção dos produtos derivados da castanhado-pará já vem sendo estudada há muitos anos, embora poucos sejam os trabalhos encontrados na literatura referentes ao assunto (Siqueira \& Regitano D'Arce, 1993).

A metodologia utilizada para a obtenção do leite foi resultado de testes prévios e adaptações dos trabalhos de Souza et al. (1987) e Siqueira \& Regitano D'Arce (1993).
A pesquisa foi conduzida utilizando, como matériaprima, amêndoas de castanhas-do-pará utilizadas para exportação, recebidas em caixas preparadas para exportação no ano de 1995.

Após prévia seleção, as amêndoas foram despeliculadas.

As castanhas despeliculadas foram prensadas em prensas hidráulicas, de laboratório, tendo um rendimento de aproximadamente $34 \%$, em peso de castanha, de óleo bruto.

A torta proveniente da prensagem foi armazenada sob congelação em sacos plásticos, na quantidade de $500 \mathrm{~g}$ cada, para melhor conservação até a obtenção da quantidade necessária para a execução da pesquisa.

Para a obtenção do leite, a torta foi homogeneizada em liqüidificador juntamente com água filtrada na proporção de 2 partes de água para uma parte de torta, até a obtenção de consistência homogênea. $O$ produto obtido foi então centrifugado em aparelho doméstico, obtendo-se o leite e a farinha úmida (não utilizada no experimento). O leite obtido foi levado para o aquecimento até a coagulação da sua fração proteica (temperatura de $85^{\circ} \mathrm{C}$ ). Após a coagulação da fração proteica, retirou-se do aquecimento e adicionou-se carboximetilcelulose (CMC) na proporção de $0,3 \% \mathrm{p} / \mathrm{v}$ e homogeneizou-se novamente em liqüidificador. Adicionaram-se às porções do leite, então, os conservantes correspondentes a cada tratamento.

Os leites foram acondicionados em saquinhos de náilon-polietileno com capacidade para $100 \mathrm{ml}$ e selados termicamente e, então, pasteurizados em banho-maria a $72 \pm 2^{\circ} \mathrm{C}$ por 20 minutos, resfriados por imersão em gelo. Após atingirem a temperatura ambiente $\left(20^{\circ} \mathrm{C}\right)$, foram armazenados sob refrigeração $\left(5 \pm 2^{\circ} \mathrm{C}\right)$ (Figura 1$)$.

\section{Análises de caracterização físico-química do extrato fluido}

a) $\mathbf{p H}$ : determinado por leitura direta em potenciômetro DIGIMED modelo DMPH-2.

b) Acidez titulável: determinada usando-se método descrito pelo Instituto Adolfo Lutz (1985).

c) Lipídios: extração feita conforme método descrito por Folch et al. (1957). Executada apenas para caracterização inicial do produto.

d) Proteína bruta: determinação feita conforme método de Kjeldahl descrito pelo Instituto Adolfo Lutz (1985). O teor de nitrogênio total da amostra, multiplicado por 5,46, conforme Hart \& Fisher (1971) fornece a quantidade de proteína bruta. Executado apenas para caracterização inicial do produto.

e) Matéria-seca: cálculo feito por diferença com o grau de umidade, que é determinado pelo método de secagem em estufa a $105^{\circ} \mathrm{C}$ até peso constante, partindo de um volume de $10 \mathrm{ml}$ de extrato fluido. Método descrito pelo Instituto Adolfo Lutz (1985) para extrato seco de leite. 


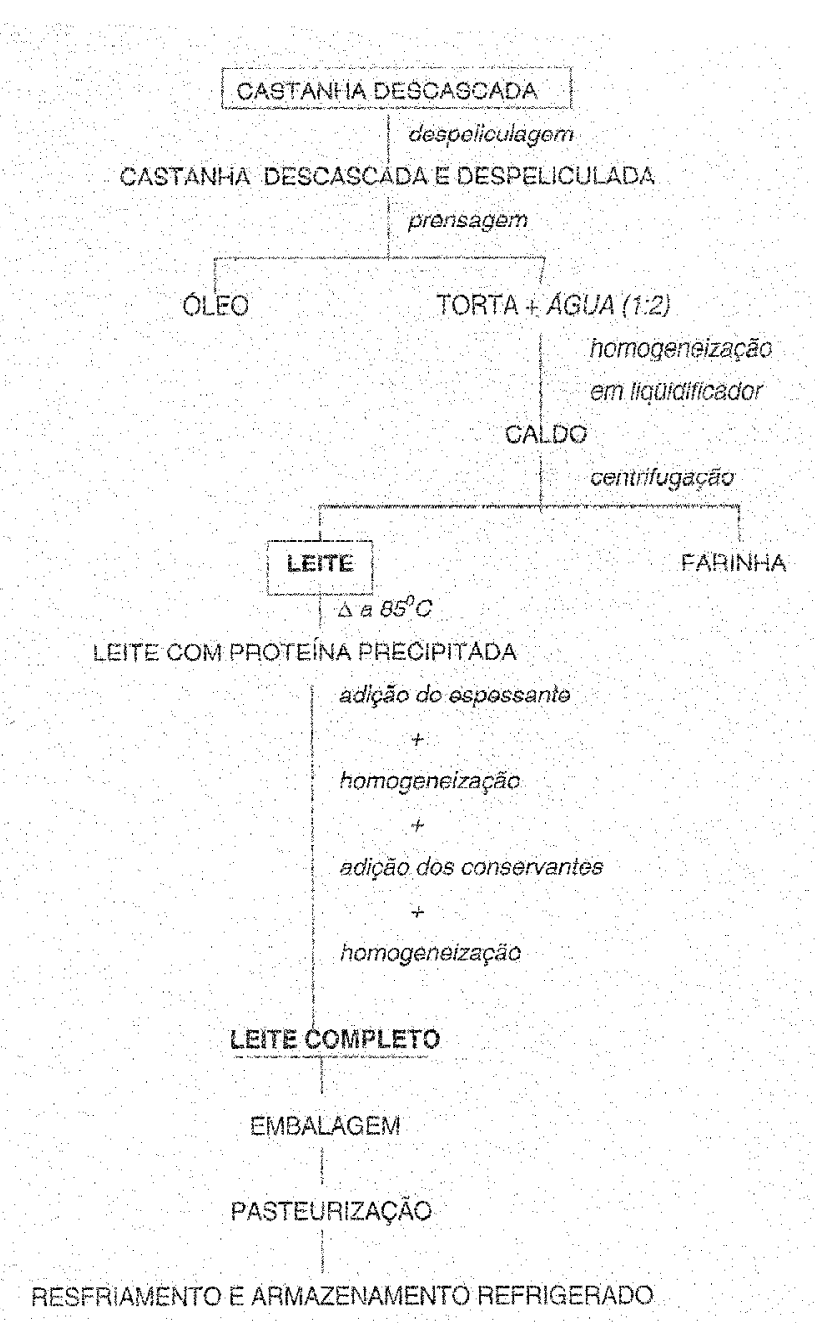

Figura 1 - Etapas do Processamento da Castanha para Obtenção do Leite.

\section{Análises microbiológicas do extrato fluido}

a) Contagem de aeróbios totais: contagem de colônias de microrganismos mesófilos aeróbios em placa, utilizando o meio PCA ("Plate Count Agar") empregando as diluições $10^{-1}, 10^{-2}, 10^{-3}, 10^{-4}, 10^{-5}$ e incubando a $32^{\circ} \mathrm{C}$ por 24/48 horas, segundo Vanderzant \& Splittstoesser (1992).

b) Microrganimos proteolíticos: contagem de microrganismos proteolíticos, utilizando PCA acrescido de $1 \%$ de leite desnatado esterilizado, empregando as diluições $10^{-1}, 10^{-2}, 10^{-3}, 10^{-4}, 10^{-5}$ e incubando a $32^{\circ} \mathrm{C}$ por $24 / 48$ horas. Faz-se, então, a contagem das colônias que apresentem um halo de proteólise ao redor, segundo (American Public Health Organization) (1972).

c) NMP (número mais provável) de coliformes totais e fecais: realizado segundo as normas da Associação Brasileira de Normas Técnicas (ABNT) (1991) para alimentos.

\section{RESULTADOS E DISCUSSÃO}

\section{Análises físico-químicas de padronização do leite de castanha-do-pará}

O produto possui a caracterização físico-química média inicial conforme TABELA 1.

Ao se compararem os resultados obtidos com os do trabalho de Regitano D'Arce \& Siqueira (1995), no dia de processamento, dos produtos sem conservantes e com conservantes, puderam-se observar valores de matériaseca inferiores $(16,3 \%$ e $16,67 \%$ respectivamente para os produtos sem e com conservantes). Quanto aos lipídios, os valores foram bastante próximos $(5,17 \%$ e $4,86 \%$ respectivamente). Quanto à proteína bruta, as autoras obtiveram valores bastante inferiores $(15,54 \%$ e $16,86 \%$ respectivamente). Parte da diferença no percentual de proteína bruta é devida à variação da matéria-seca, e pode-se supor que a utilização de um multiprocessador elétrico para a separação da torta neste experimento, em comparação com a filtragem em tecido de algodão, tenha sido responsável, também, por parte da variação obtida, pois a metodologia utilizada neste experimento baseou-se na utilizada por Regitano D’Arce \& Siqueira (1995).

\section{Análises físico-químicas de pH e acidez titulável}

Os dados médios de $\mathrm{pH}$ e acidez titulável do experimento estão apresentados nas Figuras 2 e 3.

$\mathrm{O}$ patamar inicial de $\mathrm{pH}$ variou em função do caráter mais ou menos ácido das combinações de conservantes utilizados nos tratamentos 1 e 2 , observando-se valores médios decrescentes com $\mathrm{T} 3>\mathrm{T} 1>\mathrm{T} 2(7,02>6,82>6,14)$ (Figura 2).

TABELA 1 - Caracterização físico-química média inicial do produto obtido.

Tratamento 1 Tratamento 2 Tratamento 3

\begin{tabular}{lccc}
\hline $\begin{array}{l}\text { matéria-seca } \\
(\%)\end{array}$ & 19,01 & 19,43 & 19,68 \\
$\begin{array}{l}\text { proteína bruta } \\
\text { (m.s. \%) }\end{array}$ & 21,82 & 21,33 & 21,23 \\
\hline lipídios (\%) & 5,06 & 5,51 & 4,88 \\
\hline
\end{tabular}

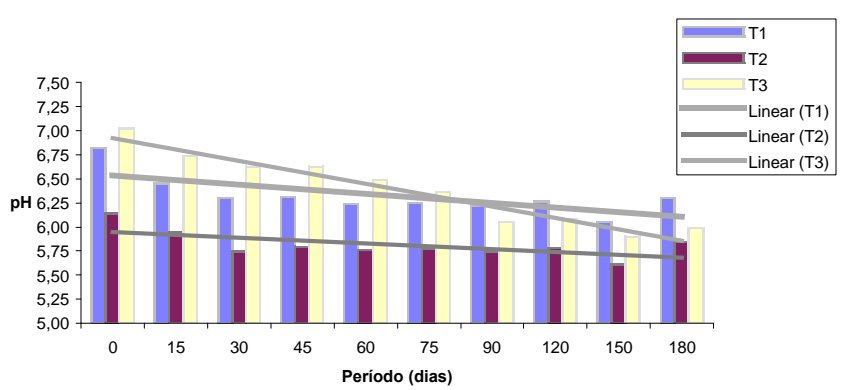

Figura 2 - Valores médios de pH do leite de castanha-do-pará, armazenado sob refrigeração por 180 dias. 
Constatou-se que houve um decréscimo mais acentuado do $\mathrm{pH}$ do $\mathrm{T} 3$ em relação aos outros tratamentos, deduzindo-se que esse produto, apenas pasteurizado e refrigerado, tenha sido menos estável ao longo dos 180 dias de armazenamento. $\mathrm{O}$ pH final médio para o T3 foi de 5,99, apresentando uma redução de 1,03 pontos em relação ao $\mathrm{pH}$ inicial (de 7,02 para $5,99)$.

Ao se compararem os tratamentos 1 e 2 , observase pequena variação nos valores de $\mathrm{pH}$ ao longo do período de armazenamento. O T1 iniciou com pH de 6,82, que caiu progressivamente até $6,05 \mathrm{com} 150$ dias de armazenamento e novamente se elevou aos 180 dias para 6,30. O T2 iniciou com pH 6,14 e caiu, de forma semelhante ao T1, até 5,61 com 150 dias, elevando-se aos 180 dias para 5,85. A amplitude de variação foi menor em $\mathrm{T} 2$, levando a concluir que o tratamento T2 tenha sido o mais estável quanto ao $\mathrm{pH}$, seguido por T1 e T3.

Os resultados de Regitano D'Arce \& Siqueira (1995) mostraram elevação em seus valores de $\mathrm{pH}$, tanto sem quanto com conservantes. Vários fatores podem ser responsáveis por esse comportamento: a combinação de conservantes, o tipo de embalagem empregada, as condições de processamento térmico, o grau de contaminação do produto.

Embora se esperasse uma maior estabilidade do T1, que, ao invés do ácido benzóico, possui os "parabens" (ésteres considerados mais eficientes na inibição do crescimento microbiológico em produtos de baixa acidez, conforme Araújo (1990)), o T2 mostrou valores de pH mais estáveis ao longo do período de armazenamento.

A acidez titulável no T1 iniciou-se com 0,21\%, havendo um pico aos 60 dias de armazenamento $(0,30 \%)$ e voltando a cair, finalizando, aos 180 dias, com 0,23\%, valor próximo ao do início (Figura 3). No T2 os valores iniciais foram os maiores $(0,26 \%)$ devido à combinação de conservantes; comportamento inverso ao do $\mathrm{pH}$. Os valores de acidez mantiveram-se estáveis por 15 dias, reduzindo-se aos 30 dias $(0,21 \%)$ e elevando-se significativamente aos 60 dias $(0,35 \%)$, caindo, então, ao patamar inicial e permanecendo praticamente estáveis até os 150 dias, quando novamente elevaram-se até os 180 dias de armazenamento.

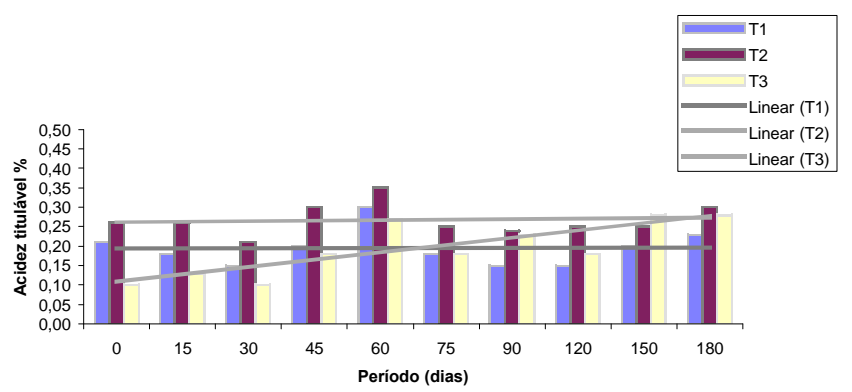

Figura 3 - Valores médios de acidez titulável \% do leite de castanha-do-pará, armazenado sob refrigeração por 180 dias.
Observando-se as curvas de T1 e T2 na Figura 3 , verifica-se que há certa coincidência nos comportamentos, havendo elevação acentuada até os 60 dias e queda dos valores após os 60 dias. Não há correlação com um decréscimo correspondente no $\mathrm{pH}$ como era de se esperar. Ocorre, em seguida, uma redução nos valores. O T1 atinge patamares inferiores, o que novamente demonstra uma maior estabilidade do T2. Percebe-se, mais uma vez, que não houve vantagem na utilização dos "parabens" adicionados no T1, conforme demonstram os valores de acidez observados.

Entretanto, as faixas máxima e mínima de acidez nunca estiveram exacerbadas em relação à conservação do produto. Basta verificar-se o trabalho de Regitano D'Arce \& Siqueira (1995), cujos valores de acidez titulável para o produto com conservantes variaram de $0,30 \%$ a $0,50 \%$.

O T3 seguiu o padrão de comportamento dos outros dois tratamentos (Figura 3). Entretanto, o patamar inicial $(0,10 \%)$ foi bem menor devido à ausência de conservantes, resultando num produto menos ácido. Houve elevação acentuada da acidez aos 60 dias $(0,27 \%)$ e os valores não retornaram ao patamar inicial, oscilando e finalizando com a acidez de $0,28 \%$. Ao se comparar, novamente, com o trabalho de Regitano D'Arce \& Siqueira (1995), houve bastante diferença no comportamento da acidez titulável também nos produtos que não receberam conservantes, sendo que as autoras obtiveram maior estabilidade dos valores de acidez, o que confirma a menor contaminação microbiológica (expressa pela contagem total) encontrada e maior estabilidade de seus produtos sem adição de conservantes.

Parte do comportamento de acidez e pH no experimento pode ser explicada por The Mesurement of acidity (1968), que considera que o processamento, armazenamento ou incubação podem causar aumento na acidez, e a deterioração microbiana freqüentemente causa uma redução marcante no $\mathrm{pH}$, especialmente em produtos de baixa acidez. Leufstedt (1990) também observa que produtos de baixa acidez são mais suscetíveis à deterioração microbiana.

\section{Análises microbiológicas}

A ausência dos grupos de coliformes totais e fecais é um indicativo da eficiência do tratamento térmico de pasteurização e da ausência de recontaminação, pois, conforme Vanderzant \& Splittstoesser (1992), a presença de coliformes em alimentos processados é um indicador útil de contaminação pós-sanitização e pósprocessamento. No processamento executado por Ribeiro et al. (1981), a pasteurização em banho-maria pelo sistema "hot pack", por 5 minutos a $90^{\circ} \mathrm{C}$, seguida de refrigeração, foi eficiente para eliminar o grupo dos coliformes totais, enquanto que no produto exclusivamente sob refrigeração encontraram-se 240 UFC mL $\mathrm{mL}^{-1}$ coliformes totais. Este produto resistiu apenas por 48 horas. 
O comportamento dos microrganismos mesófilos pode ser observado na Figura 4, cujos resultados são expressos em logaritmo decimal de UFC $\mathrm{mL}^{-1}$.

Os tratamentos mais estáveis foram o T1 e o T2, com contagens relativamente estáveis ao longo do período

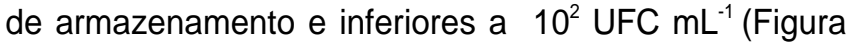
4). O T3 mostrou resultados levemente crescentes até 15 dias de armazenamento e, a partir de então, o crescimento dos microrganismos foi exponencial, atingindo o máximo de contagem aos 75 dias $\left(10^{5} \mathrm{UFC} \mathrm{mL}^{-1}\right)$. A população reduziu-se, gradativamente, ao patamar inicial, ao longo do restante do período de armazenamento, provavelmente devido à exaustão de nutrientes, com alteração drástica das condições do meio.

Esse comportamento de crescimento de mesófilos para os tratamentos ao longo do período de armazenamento demonstrou a efetividade da adição dos conservantes nos T1 e T2. Genigeorgis (1981) considera que a adição de conservantes é um fator importante para o aumento da habilidade do alimento em resistir ao crescimento microbiano, mas apenas auxiliam no controle da deterioração, não prevenindo o crescimento de microrganismos. Os grupos prováveis seriam os termófilos, os mesófilos (incluindo os termodúricos, que crescem lentamente sob refrigeração, segundo Vanderzant \& Splittstoesser (1992)) e psicrotróficos (multiplicam-se em temperatura de refrigeração).

A evolução do crescimento dos microrganismos proteolíticos pode ser observada na Figura 5, que apresenta os resultados médios de contagem transformados em logaritmo decimal de UFC $\mathrm{mL}^{-1}$.

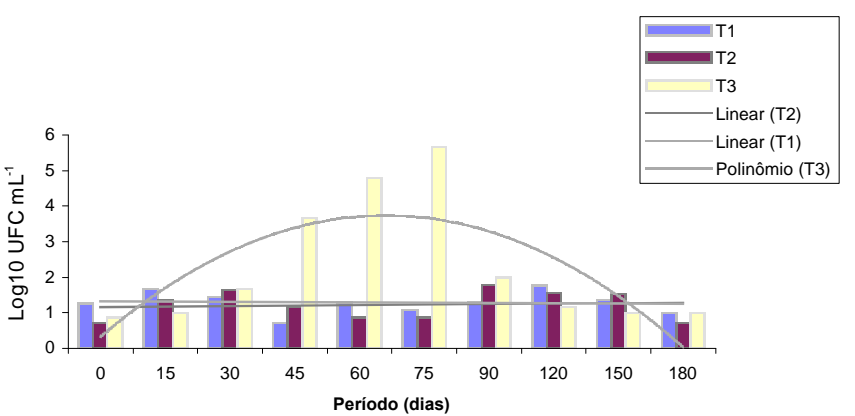

Figura 4 - Contagens de microrganismos mesófilos no leite de castanha-do-pará, armazenado sob refrigeração por 180 dias.

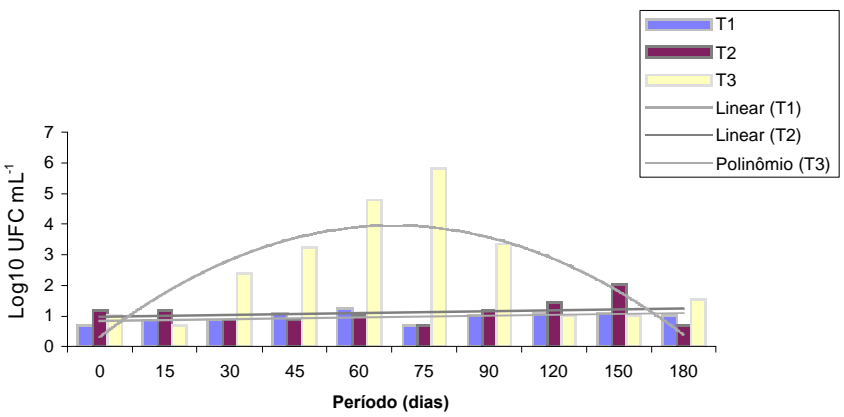

Figura 5 - Contagens de microrganismos proteolíticos no leite de castanha-do-pará, armazenado sob refrigeração por 180 dias.
Os microrganismos proteolíticos cresceram pouco nos tratamentos que receberam conservantes, T1 e T2,

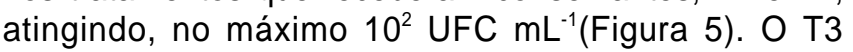
apresentou crescimento exponencial a partir dos 15 dias de armazenamento até o máximo de crescimento ao 75 dias, quando, então, houve um decréscimo significativo da população até permanecer praticamente estável dos 120 dias em diante. Esse comportamento é bastante semelhante ao dos microrganismos mesófilos no T3.

Deduz-se desse comportamento do T3 que possivelmente os microrganismos resistentes ao tratamento térmico tiveram condições facilitadas para sua multiplicação, atribuindo-se a eles, além do caráter mesofílico, o proteolítico e psicrotrófico. Pode-se lembrar que, conforme Vanderzant \& Splittstoesser (1992), a proteólise pode ocorrer em temperaturas de refrigeração. Observa-se que a adição de conservantes influenciou de alguma forma, seja pela redução do pH, seja pelo efeito inibitório dos ácidos utilizados como conservantes, o crescimento dos microrganismos nos produtos sob refrigeração.

\section{CONCLUSÕES}

- O processo tecnológico de obtenção do leite de castanha-do-pará empregado levou a um produto com um teor de proteína significativo de 21,19\% sobre a matéria-seca, lipídio baixo, ao redor de 5\%, pouco superior ao do leite bovino integral. Consistiu, assim, em alternativa viável para a complementação energético-proteica de dietas, podendo até ser utilizado em programas de merenda escolar nas regiões produtoras, onde há abundância da matéria-prima.

- O emprego de pasteurização e refrigeração permitiram que o produto se mantivesse estável microbiologicamente por, pelo menos, 30 dias, podendo ser classificado como semi-perecível.

- O efeito aditivo de pasteurização, refrigeração e adição de conservantes garantiu a estabilidade do produto durante os 180 dias de armazenamento.

- Os parâmetros de pH e acidez titulável podem auxiliar no monitoramento da estabilidade do produto.

- A ausência dos grupos de coliformes totais e fecais garantiu que as condições de higiene no processamento e armazenamento do produto fossem consideradas satisfatórias.

\section{REFERÊNCIAS BIBLIOGRÁFICAS}

ASSOCIAÇÃO BRASILEIRA DE NORMAS TÉCNICAS. Bactérias coliformes totais, coliformes fecais e Escherichia coli em alimentos: determinação do número mais provável (NMP). NB-3463. Rio de Janeiro: ABNT, 1991. $7 \mathrm{p}$.

AIRES, J.; MAGALHÃES, J.M.; HESSE, S.R.; SANTOS, J.C.F. Proposta-base das diretrizes para formulação de um programa de incentivo à produção de castanha-do-brasil (Bertholletia excelsa - H.B.K.) In: ENCONTRO BRASILEIRO DE ENGENHEIROS FLORESTAIS, 4., Rio de Janeiro, 1986. Proceedings. Rio de Janeiro: 1986. p.143-150. 
AMERICAN PUBLIC HEALTH ASSOCIATION. Standard methods for the examination of dairy products. 13.ed. Washington: APHA, 1972. 345p.

ARAÚJO, J.M.A. Conservadores químicos em alimentos. Boletim da Sociedade Brasileira de Ciência e Tecnologia de Alimentos, v.24, p.192-210, 1990.

CACEX. Informação Semanal, v.19, n.901, 1984.

FOLCH, J.; LEES, M.; SLOANNE STANLEY, G.H. A simple method for the isolation and purification of total lipids from animal tissues. Journal of Biological Chemistry, v.226, p.497-509, 1957.

GENIGEORGIS, A.C. Factors affecting the probability of growth of patogenic microorganisms in foods. Journal of the American Veterinary Medical Association, v.79, p.1410-1417, 1981.

HART, F.L.; FISHER, H.L. Modern food analysis. New York: Springer Verlag, 1971. 283p.

INSTITUTO ADOLFO LUTZ. Normas analíticas do Instituto Adolfo Lutz: métodos químicos e físicos para análise de alimentos. 3.ed. São Paulo, 1985. v.1, p.21-22; 25-26; 44-45.

LEUFSTEDT, G. Opportunities for future diversification of the coconut industry. Oleagineux, v.45, p.505-508, 1990.

LOCATELLI, M.; SOUZA, V.F. de. Castanha-do-Brasil: características agronômicas, produção de mudas e propagação vegetativa. Porto Velho: EMBRAPA, UEPAE, 1990. 11p. (Circular Técnica, 17).

REGITANO D'Arce, M.A.B.; SIQUEIRA, F.M. Obtenção do leite e farinhas de castanha do Pará (Bertholletia excelsa). In: CONGRESSO E EXPOSIÇÃO LATINOAMERICANOS SOBRE ÓlEOS E GORDURAS, 6., Campinas, 1995. Proceedings. Campinas: 1995. p.265-267.

RIBEIRO, C.C.; ARAÚJO, C.M.F. de; FERREIRA, R.S. Ensaio sobre a obtenção e conservação do leite de castanha-doBrasil (Bertholletia excelsa H.B.K.). Belém: UFP, 1981. $42 p$.
RIBEIRO, M.A. de A. Aproveitamento tecnológico de castanhasdo-brasil (Bertholletia excelsa): estudo da qualidade de conservação. Piracicaba, 1992. 117p. Dissertação (Mestrado) - Escola Superior de Agricultura "Luiz de Queiroz", Universidade de São Paulo.

SANT'ANNA, N.M.G. Desenvolvimento e estudo de estabilidade e embalagem de alimentos formulados contendo castanhado-pará. Viçosa, 1985. Dissertação (Mestrado) Universidade Federal de Viçosa.

SIQUEIRA, F.M. de; REGITANO D'ARCE, M.A.B. Obtenção de produtos da castanha-do-pará (leite e farinha) com vistas à popularização do seu consumo. Piracicaba: Depto. de Ciência e Tecnologia Agroindustrial, 1993. 15p. (Relatório FAPESP).

SOUZA, M.L.de; HOLANDA, L.F.F.de; MAIA, G.A.; GASPAR JUNIOR, J.C.; FIGUEIREDO, R.W.de. Processamento e estabilidade do leite de castanha-do-brasil (Bertholletia excelsa H.B.J.). Ciência Agronômica, v.18, p.137-146, 1987.

TEIXEIRA, E.A.M.; MAIA, G.A.; HOLANDA, L.F.F. de; OLIVEIRA, G.S.F. de; GASPAR JÚNIOR, J.C.; FIGUEIREDO, R.W. de. Processo alternativo para conservação do leite de coco produzido para consumo comercial. Pesquisa Agropecuária Brasileira, v.24, p.761-768, 1989.

THE MESUREMENT of acidity. In: LABORATORY MANUAL FOR FOOD CANNERS AND PROCESSORS. Westport: AVI Publishing, 1968. v.2, cap.19, p.168-189.

VANDERZANT, C.; SPLITTSTOESSER, Don F. Compendium of methods for the microbiological examination of foods. 3.ed. Washington: APHA, 1992. 1219p.

VIANNA, P. R. Estudo da castanha-do-Brasil. Brasília: Ministério da Agricultura, Comissão de Financiamento da Produção, 1972.

YOKOYA, F.; ANTUNES, A.J.; JORDÃO, B.A. Deterioração da castanha-do-pará: II. Armazenamento das castanhas. Revista Brasileira de Tecnologia, v.2, p.117-120, 1971.

$\overline{\text { Recebido em } 11.01 .00}$ 